\title{
Article \\ Controlled Lattice Thermal Conductivity of Transparent Conductive Oxide Thin Film via Localized Vibration of Doping Atoms
}

\author{
Young Joong Choi ${ }^{1}$, Ho Yun Lee ${ }^{1}$, Seohan Kim ${ }^{2,3, *}$ and Pung Keun Song ${ }^{1, *}$ \\ 1 Department of Materials Science and Engineering, Pusan National University, Busan 46241, Korea; \\ yjchoi0782@pusan.ac.kr (Y.J.C.); dbs0770@pusan.ac.kr (H.Y.L.) \\ 2 Department of Materials Science and Engineering, Ångström Laboratory, Uppsala University, \\ 75321 Uppsala, Sweden \\ 3 Materials Technology and Research, Pusan National University, Busan 46241, Korea \\ * Correspondence: seohan.kim@angstrom.uu.se (S.K.); pksong@pusan.ac.kr (P.K.S.)
}

check for updates

Citation: Choi, Y.J.; Lee, H.Y.; Kim, S.; Song, P.K. Controlled Lattice Thermal Conductivity of Transparent Conductive Oxide Thin Film via Localized Vibration of Doping Atoms. Nanomaterials 2021, 11, 2363. https:// doi.org/10.3390/nano11092363

Academic Editors: David

Muñoz-Rojas, Gyaneshwar P.

Srivastava and Daniel Bellet

Received: 6 August 2021

Accepted: 9 September 2021

Published: 11 September 2021

Publisher's Note: MDPI stays neutral with regard to jurisdictional claims in published maps and institutional affiliations.

Copyright: (C) 2021 by the authors. Licensee MDPI, Basel, Switzerland. This article is an open access article distributed under the terms and conditions of the Creative Commons Attribution (CC BY) license (https:/ / creativecommons.org/licenses/by/ $4.0 /)$.

\begin{abstract}
Amorphization using impurity doping is a promising approach to improve the thermoelectric properties of tin-doped indium oxide (ITO) thin films. However, an abnormal phenomenon has been observed where an excessive concentration of doped atoms increases the lattice thermal conductivity $\left(\kappa_{1}\right)$. To elucidate this paradox, we propose two hypotheses: (1) metal hydroxide formation due to the low bond enthalpy energy of $\mathrm{O}$ and metal atoms and (2) localized vibration due to excessive impurity doping. To verify these hypotheses, we doped $\mathrm{ZnO}$ and $\mathrm{CeO}_{2}$, which have low and high bond enthalpies with oxygen, respectively, into the ITO thin film. Regardless of the bond enthalpy energy, the $\kappa_{1}$ values of the two thin films increased due to excessive doping. Fourier transform infrared spectroscopy was conducted to determine the metal hydroxide formation. There was no significant difference in wave absorbance originating from the $\mathrm{OH}$ stretching vibration. Therefore, the increase in $\kappa_{1}$ due to the excessive doping was due to the formation of localized regions in the thin film. These results could be valuable for various applications using other transparent conductive oxides and guide the control of the properties of thin films.
\end{abstract}

Keywords: thermoelectric thin film; transparent conductive oxide; localized vibration; thermal conductivity; magnetron sputtering

\section{Introduction}

As regulations on carbon emissions are strengthened to prevent global warming, numerous studies of renewable energy are being conducted in various fields to achieve higher energy conversion efficiencies [1-5]. Thermoelectricity is a promising renewable energy source that can replace fossil fuels because it can produce energy through waste heat, unlike other renewable energy sources. To employ thermoelectric (TE) materials in various devices and fields, extensive studies have been carried out to improve the energy conversion efficiency of thin-film thermoelectric materials [6-11]. Particularly, as a transparent TE material, tin-doped indium oxide $\left(\mathrm{In}_{2} \mathrm{O}_{3}: \mathrm{SnO}_{2}\right.$, ITO) thin film is promising owing to its high electrical conductivity, chemical stability, low toxicity, and low price compared to TE alloys [12-15]. Accordingly, numerous studies have been carried out to improve the physical properties of ITO, including chemical treatment, impurity doping, and heat treatment, to improve the efficiency compared to opaque TE materials [16-20]. Among them, heat treatment to improve the thin film crystallinity is not promising for ITO-based TE materials because the high crystallinity increases the carrier density $(n)$ of the thin film, which results in a decrease in the Seebeck coefficient $(S)$ and degrades the thermoelectric figure of merit (ZT) owing to the increased thermal conductivity of electrons. On the other hand, a suitable level of impurity doping can induce a high electrical conductivity without 
increasing $n$ because of the high carrier mobility $(\mu)$ [17,21,22]. The electrical conduction of ITO is achieved with a conduction band minimum by overlapping of the In $5 s$ orbital, which is insensitive to metal-oxide bond angle variation in the amorphous structure [23]. Hence, unlike other materials with directional covalent bonds, such as a-Si, the $\mu$ of ITO can be maintained in an amorphous thin film by the nondirectional ionic bonding originating from the metal $s$ orbital. Regarding metal oxide thin films, which enable a high $\mu$ in an amorphous structure, impurity-doped amorphous ITO thin films are attractive materials for TE thin films because they can have a comparably low $n$, which decreases the electron thermal conductivity $\left(\kappa_{\mathrm{e}}\right)$ while maintaining a high electrical conductivity $(\sigma)$ owing to the high $\mu$.

In our previous study, the microstructure of the ITO thin film was manipulated to control $n$ and thermal conductivity without reducing the electrical conductivity of the thin film by doping with $\mathrm{ZnO}$ [24]. The total thermal conductivity $\left(\kappa_{\text {tot }}\right)$ decreased with the increase in the $\mathrm{ZnO}$ concentration. The highest $\mathrm{ZT}(0.0627)$ was achieved with an optimized level of $\mathrm{ZnO}$ doping. However, an abnormal phenomenon of lattice thermal conductivity $\left(\kappa_{1}\right)$ increase was observed when the $\mathrm{ZnO}$ concentration exceeded the optimized value, despite the assumption of further progress to a randomly disordered structure proportional to the $\mathrm{ZnO}$ concentration. Several studies have been carried out on the increase in $\kappa_{1}$ in relation to the dopant concentration $[25,26]$. To demonstrate this paradoxical phenomenon, two hypotheses are proposed to explain the $\kappa_{1}$ increase: (1) metal hydroxide formation due to the low bond enthalpy energy of $\mathrm{Zn}$ and $\mathrm{O}$ and (2) $\mathrm{Zn}$ localization due to excessive impurity doping. Further experimental studies are needed to determine the correlation between $\kappa_{1}$ and dopant concentration. To clarify the factor responsible for the increase in $\kappa_{1}$ with a high dopant concentration, an atom that has a high bond enthalpy with $\mathrm{O}$ can be employed as a symmetrical dopant.

In this study, we compared the $\kappa_{1}$ values of $\mathrm{ZnO}$ - and $\mathrm{CeO}_{2}$-doped ITO, which have low and high bond enthalpies with $\mathrm{O}$, respectively (Zn-O: $159 \pm 4 \mathrm{~kJ} / \mathrm{mol}$, Ce$\mathrm{O}: 795 \pm 8 \mathrm{~kJ} / \mathrm{mol}$ ). The ITO thin film was amorphized by doping with $\mathrm{ZnO}$ or $\mathrm{CeO}_{2}$ and exhibited a $\sigma$ and low $\kappa_{1}$ up to the critical level of doped $\mathrm{ZnO}$ or $\mathrm{CeO}_{2}$. In addition, we investigated the infrared absorbance using Fourier transform infrared (FTIR) spectroscopy to verify whether this phenomenon is due to the formation of metal hydroxide bonds because of the low bond enthalpy energy between the doped atom and oxygen or formation of localized regions in the amorphous material. There was no remarkable difference in the infrared absorbance of the doped thin film, regardless of the different bond enthalpy energies with oxygen. Thus, the increased lattice thermal conductivity due to the excessive doping of $\mathrm{ZnO}$ and $\mathrm{CeO}_{2}$ originates from localized vibration. We expect that these results can be used for other transparent conductive oxide (TCO)-based thin-film systems and significantly contribute to the development of the TCO thin-film field.

\section{Materials and Methods}

\subsection{Thin-Film Fabrication}

ITO thin films were deposited on a nonalkali glass using a single sintered ITO target $\left(\mathrm{SnO}_{2}: 10 \mathrm{wt} \%\right)$. ITO:Zn and ITO:Ce thin films were deposited by employing $\mathrm{ZnO}$ and $\mathrm{CeO}_{2}$ targets and cosputtering with an ITO target $\left(\mathrm{SnO}_{2}: 10 \mathrm{wt} \%\right)$ via a magnetron cosputtering system on the nonalkali glass. The base pressure of the deposition process was $1.5 \times 10^{-5}$ Torr. The total gas pressure was maintained at 1.0 Pa using an Ar gas flow of $20 \mathrm{sccm}$. All the thin-film samples were deposited to a thickness of $150 \mathrm{~nm}$.

\subsection{Thin-Film Characterization}

The microstructures of the thin films were analyzed using X-ray diffraction (XRD; D8 Advance, Bruker, Billerica, MA, USA). A Hall effect measurement system (HMS2000, Ecopia, Anyang, Korea) was employed to measure the electrical properties of the thin films. The transmittance was estimated using an ultraviolet (UV)-visible analysis (UV1800 , Shimadzu, Kyoto, Japan). The $\kappa_{\text {tot }}$ value of the thin film was measured using the 
time-domain thermoreflectance (TDTR) method, which uses a $765 \mathrm{~nm}$ Ti:sapphire laser. An Al thin film of $85 \mathrm{~nm}$ thickness was deposited on the ITO:Zn and an ITO:Ce thin film of $150 \mathrm{~nm}$ thickness as the thermal transducer layer of a femtosecond pulsed light beam. The volumetric heat capacity of ITO:Zn, ITO:Ce, and the Al thin film was assumed to be the same as ITO and Al bulk materials $[27,28]$. The $\kappa_{\mathrm{e}}$ value was calculated using the equation $\kappa_{\mathrm{e}}=L_{0} T / \rho$ via the carrier density obtained by Hall measurements, where $L_{0}, T$, and $\rho$ are the Lorentz coefficient, absolute temperature, and resistivity, respectively. After the measurement and calculation, $\kappa_{1}$ was obtained by subtracting $\kappa_{\mathrm{e}}$ from $\kappa_{\text {tot }}$. Finally, the $\mathrm{OH}$ stretching vibration of the doped ITO thin film was measured using FTIR spectroscopy (Vertex 80v, Bruker, Billerica, MA, USA).

\section{Results and Discussion}

To analyze the influence of the dopant material in the ITO thin film on the crystallinity of the thin film, $\mathrm{ZnO}$ (ITO:Zn) and $\mathrm{CeO}_{2}$ (ITO:Ce) were deposited on a nonalkali glass substrate. As shown in Figure 1, the undoped ITO thin film exhibits the preferred orientations (222) and (400), which indicates that the pure ITO has a polycrystalline structure.

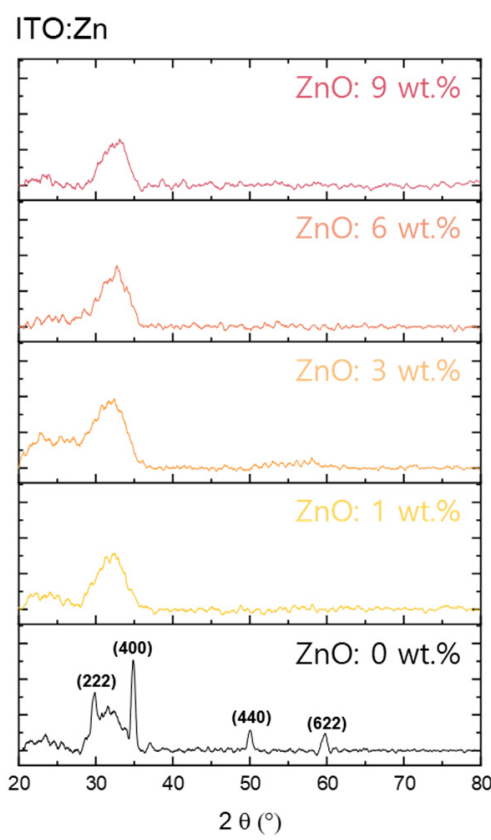

(a)

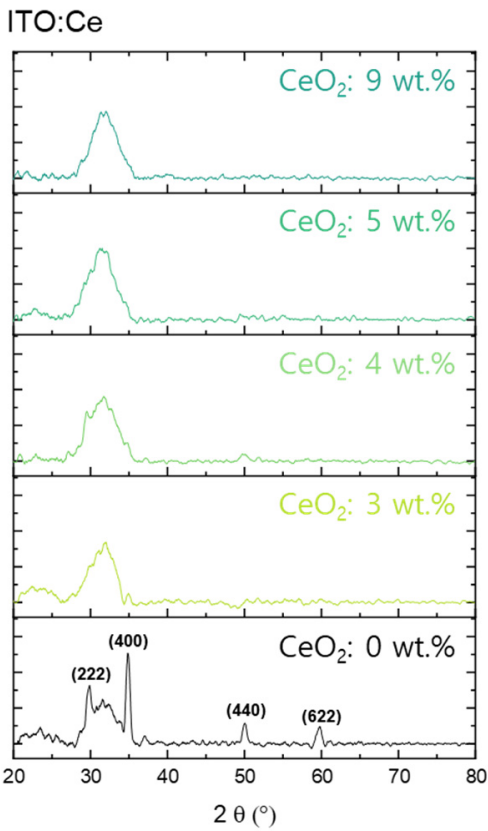

(b)

Figure 1. XRD patterns of (a) ZnO-doped ITO and (b) $\mathrm{CeO}_{2}$-doped ITO. The pure ITO exhibits a polycrystalline structure. The crystal structure of ITO doped with $\mathrm{ZnO}$ and $\mathrm{CeO}_{2}$ becomes amorphous even with a small level of doping. There is no change in the diffraction pattern when the doping amount is further increased.

In the case of the doped ITO (ITO:Zn or ITO:Ce), both thin films exhibited amorphous structures regardless of the doping amount. With the increase in the doping amount of $\mathrm{ZnO}$ and $\mathrm{CeO}_{2}$, the main peaks of (222) and (400) of ITO disappeared and became broad, which indicates that the thin film transformed the microstructure from polycrystalline to amorphous. Despite the bond enthalpy energy difference of the doped atom with oxygen, the ITO thin film was amorphized even with a small amount of doped $\mathrm{ZnO}$ and $\mathrm{CeO}_{2}$.

The electrical properties of the ITO:Zn and ITO:Ce thin films are shown in Figure 2. In the case of ITO:Zn, the lowest resistivity $(\rho)$ was observed for $1 \mathrm{wt} \%$ of $\mathrm{ZnO}$ owing to the formation of an amorphous-like ternary compound. At concentrations higher than $1 \mathrm{wt} \%$, the $n$ of the ITO: $\mathrm{Zn}$ thin film decreased as a function of the $\mathrm{ZnO}$ concentration $[16,29,30]$. In the case of $\mathrm{CeO}_{2}$, the $\rho$ of the ITO:Ce thin film decreased up to $3 \mathrm{wt} \%$; above this 
concentration, $\rho$ increased. Despite the difference in bond enthalpy with oxygen, both ITO samples exhibited typical electrical property trends in relation to the dopant concentration.

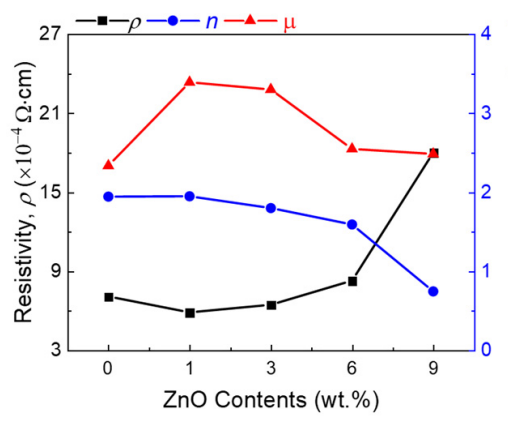

(a)
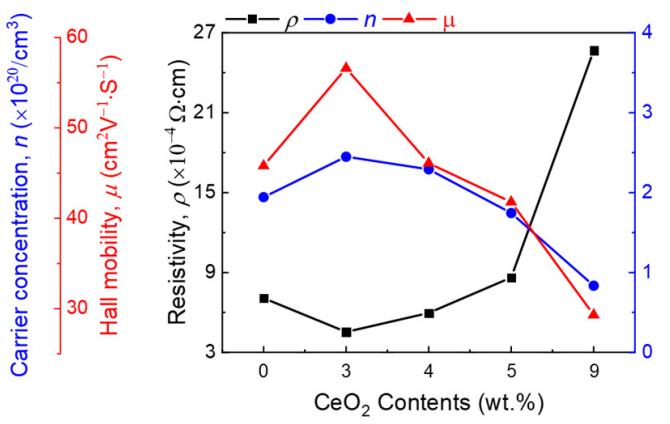

(b)

Figure 2. Comparison of electrical properties of (a) $\mathrm{ZnO}$-doped ITO and (b) $\mathrm{CeO}_{2}$-doped ITO depending on the concentration of doping atoms. With a smaller amount of doping, the resistivities of both thin films decrease. On the other hand, excessive doping degrades the electrical properties of the thin film.

The $S$ value was calculated using the Mott equation with the measured $n$ to analyze the effect of $\mathrm{Zn}$ and $\mathrm{Ce}$ atoms with different bond enthalpy energies on the thermoelectric performance of the thin film. For metal and degenerated semiconductors, the Mott equation is

$$
S=\frac{8 \pi^{2} k_{B}^{2}}{3 e h^{2}}\left(\frac{\pi}{3 n}\right)^{\frac{2}{3}} m^{*} T,
$$

where $k_{\mathrm{B}}, h, m^{*}, e, n$, and $T$ are the Boltzmann constant, Planck's constant, effective mass $\left(0.561 m_{e}=5.110 \times 10^{-31} \mathrm{~kg}\right)$, electron charge, majority charge carrier density, and absolute temperature, respectively [31]. As shown in Equation (1), the $S$ value is proportional to $n^{-2 / 3}$. Figure 3 shows $S$ values plotted in relation to $n^{-2 / 3}$, and it shows a linear proportional relationship with respect to $n^{-2 / 3}$. The ITO:Zn thin film has a lower $n$ than that of ITO:Ce, which leads to a relatively higher $S$ at a $\mathrm{ZnO}$ content of $1 \mathrm{wt} \%$. The highest $S$ was obtained at $9 \mathrm{wt} \%$ owing to the considerable decrease in $n$. With the decrease in $n$ owing to the increased doping amount of $\mathrm{CeO}_{2}$, ITO:Ce exhibited a relatively low $S$ at 9 wt $\%$.

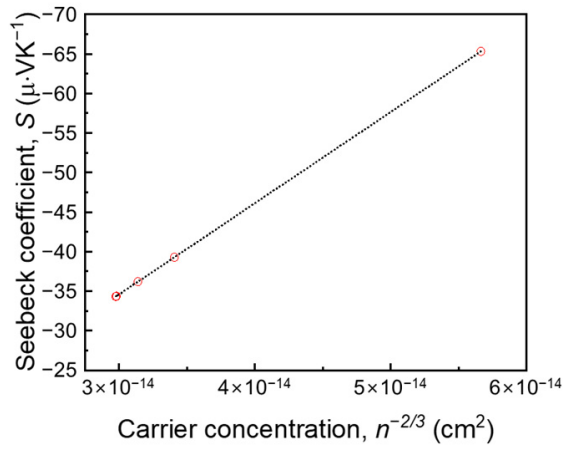

(a)

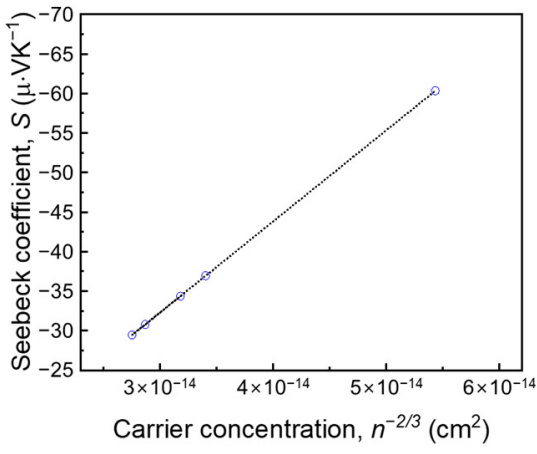

(b)

Figure 3. Seebeck coefficients $(S)$ and $n^{-(2 / 3)}$ of (a) $\mathrm{ZnO}$-doped ITO and (b) $\mathrm{CeO}_{2}$-doped ITO at various dopant concentrations. The Mott equation for metals and degenerated semiconductors was employed to calculate $S$ using the measured carrier density. 
Figure 4 shows the $\kappa_{\text {tot }}, \kappa_{\mathrm{e}}$, and $\kappa_{1}$ values of (a) ITO:Zn, (b) ITO:Ce, and (c) ZT of the ITO:Zn and ITO:Ce thin films. The ZT values were calculated using

$$
\mathrm{ZT}=\sigma S^{2} T / \kappa_{\text {tot }}
$$

where $\sigma, S, T$, and $\kappa_{\text {tot }}$ are the electrical conductivity, Seebeck coefficient, absolute temperature, and total thermal conductivity, respectively. The highest ZT (0.0558) was obtained at the highest $\mathrm{ZnO}$ dopant concentration owing to the low thermal conductivity. These results indicate relatively high thermoelectric performance in the recently reported TCO-based ntype thermoelectric material $[7,9,32,33]$. The $\kappa_{1}$ value was obtained by $\kappa_{\text {tot }}$ and $\kappa_{\mathrm{e}}$, calculated using $\kappa_{\mathbf{e}}=L_{0} T / \rho$, where $L_{0}, T$, and $\rho$ are the Lorentz coefficient, absolute temperature, and resistivity, respectively. The $\kappa_{1}$ value can then be obtained using $\kappa_{\text {tot }}=\kappa_{1}+\kappa_{\mathrm{e}}$. Regardless of the dopant atom, $\kappa_{\text {tot }}$ decreased with the increase in the doping concentration. These trends are affected by the weakened electrical properties and amorphization of the microstructure.

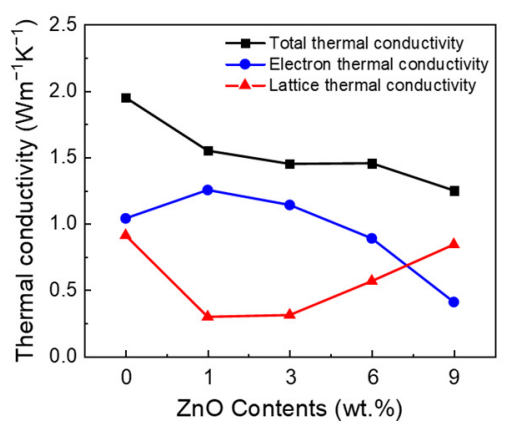

(a)

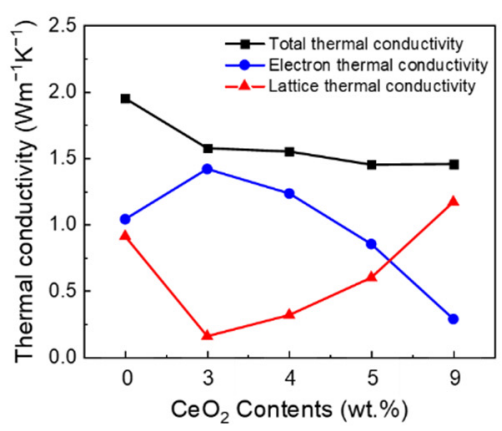

(b)

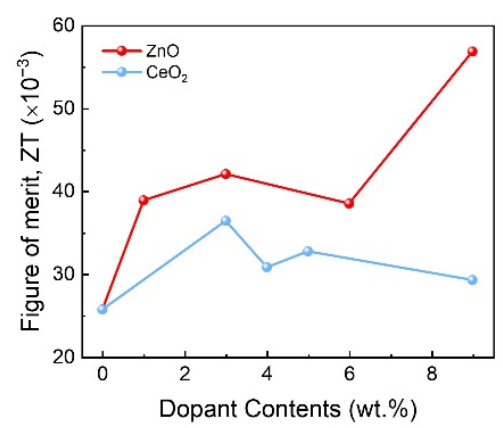

(c)

Figure 4. Dependence of the thermal conductivities of the (a) $\mathrm{ZnO}$-doped ITO and (b) $\mathrm{CeO}_{2}$-doped ITO on the doping concentration. (c) Thermoelectric figures of merit (ZT) of $\mathrm{ZnO}$ - and $\mathrm{CeO}_{2}$-doped ITO. The lattice thermal conductivity increased above a certain doping concentration.

However, an abnormal phenomenon of $\kappa_{1}$ increase above certain dopant concentrations was observed for both $\mathrm{ZnO}$ - and $\mathrm{CeO}_{2}$-doped ITO. As mentioned previously, the impurity doping in thin films causes disordered crystallinity, which deteriorates $\kappa_{1}$. Therefore, $\kappa_{1}$ should also be decreased; however, above a certain concentration, $\kappa_{1}$ is slightly increased. We propose two hypotheses to explain the $\kappa_{1}$ increase: (1) metal hydroxide formation and (2) localization of excessive dopant atoms.

Figure 5 shows the FTIR spectroscopy results for (a) ITO:Zn and (b) ITO:Ce to verify the presence of metal hydroxide in the doped ITO in relation to the dopant material. The FTIR spectroscopy analysis showed wavenumbers of 650 to $4000 \mathrm{~cm}^{-1}$. The peaks at $1023.49-1026.37 \mathrm{~cm}^{-1}$ are related to the phonon mode of the $\mathrm{In}_{2} \mathrm{O}_{3}$ lattice. The OH stretching vibration mode is related to the wavenumber of approximately $3240 \mathrm{~cm}^{-1}$ [34-39]. The wavenumber region of 650 to $1500 \mathrm{~cm}^{-1}$ corresponds to the typical signal of the ITO thin film, without significant difference, especially near the $1500 \mathrm{~cm}^{-1}$ peak, which originates from $\mathrm{O}-\mathrm{H}$ bending vibration of absorption water [40-42]. In addition, the $\mathrm{OH}$ stretching vibration region (wavenumbers around $3240 \mathrm{~cm}^{-1}$ ) did not show any signals for either ITO:Zn or ITO:Ce thin films despite a high doping concentration of $\mathrm{ZnO}$ and $\mathrm{CeO}_{2}$ ( $9 \mathrm{wt} \%$ ). This provides clues that the $\kappa_{1}$ increase above the specific dopant concentration is not related to metal hydroxide formation but originates from localized vibration due to the excessive dopant amount. Therefore, the localized region generated by excessive doping of $\mathrm{ZnO}$ and $\mathrm{CeO}_{2}$ becomes a new pathway for heat transfer in ITO and suppresses phonon scattering by cations, leading to the increase in $\kappa_{1}[25,43]$. 


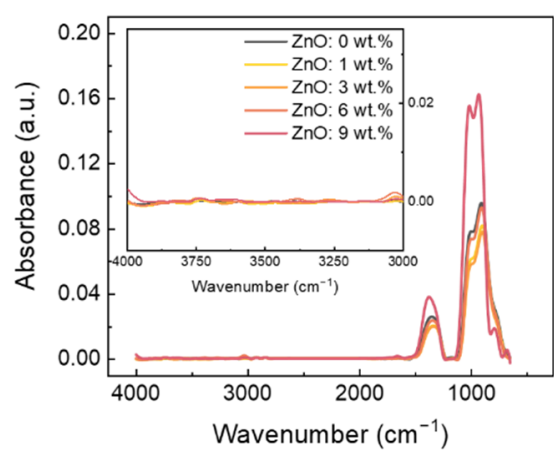

(a)

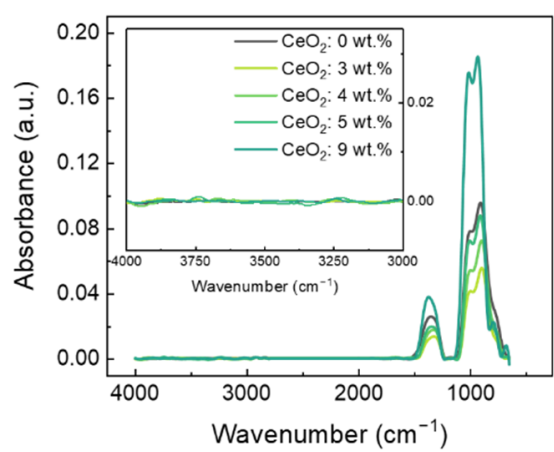

(b)

Figure 5. FTIR spectroscopy of (a) ZnO-doped ITO and (b) $\mathrm{CeO}_{2}$-doped ITO. The inset shows a detail of the $\mathrm{OH}$ stretching vibration area. Although $\mathrm{Zn}$ and Ce have different bond enthalpies with oxygen, there is no change in the $\mathrm{OH}$ stretching vibration region according to the doping amount.

\section{Conclusions}

In this study, we prepared ITO:Zn and ITO:Ce thin films with various dopant concentrations to verify the reason for the increase in $\kappa_{1}$ above a certain dopant concentration. The proposed hypotheses were (1) metal hydroxide formation and (2) localized impurity vibration. We employed $\mathrm{Zn}$ and $\mathrm{Ce}$, with low and high bond enthalpies with oxygen atoms, respectively. The pure ITO thin film exhibited a polycrystalline structure, while, regardless of the dopant atom, the doped ITO exhibited an amorphous structure. Although there was a difference between the bond enthalpy energies of $\mathrm{Zn}$ and Ce with $\mathrm{O}$, the electrical properties of the thin films deteriorated owing to the decrease in $n$ originating from the doping in both ITO:Zn and ITO:Ce. Both ITO:Zn and ITO:Ce exhibited the lowest thermal conductivities at $9 \mathrm{wt} \%$ because of the reduced $\kappa_{\mathrm{e}}$ due to the significant $n$ reduction. The $\kappa_{1}$ value was increased by excessive doping regardless of the bond enthalpy energy, which indicates that the bond enthalpy does not affect the increase in $\kappa_{1}$. The reason for the increase in $\kappa_{1}$ was determined by the FTIR spectroscopy results; there was no notable difference in the wavenumber of the $\mathrm{OH}$ stretching vibration. The wavenumber region of the $\mathrm{OH}$ stretching vibration area did not exhibit any signal, which indicated that the increase in $\kappa_{1}$ did not originate from metal hydroxide formation but from localized vibration with the excessive doping of atoms. We think that these results will guide the future control of the properties of thin films and contribute to next-generation thin-film applications.

Author Contributions: Conceptualization, Y.J.C., S.K., and P.K.S.; methodology, H.Y.L.; validation, Y.J.C., S.K., and P.K.S.; resources, P.K.S.; data curation, Y.J.C., H.Y.L., and S.K.; writing-original draft preparation, Y.J.C.; writing-review and editing, S.K. and P.K.S.; visualization, S.K.; supervision, S.K. and P.K.S.; project administration, P.K.S.; funding acquisition, P.K.S. All authors have read and agreed to the published version of the manuscript.

Funding: This study was supported by the Basic Science Research Program through the National Research Foundation of Korea funded by the Ministry of Education (2019R1A6A3A01091664) and partly supported by R\&D Platform Establishment of Eco-Friendly Hydrogen Propulsion Ship Program (No. 20006644) and Ministry of Environment (G232019012551). And this research was supported by the BK21 FOUR Program (NO.4120200513801) funded by the Ministry of Education (MOE, Korea) and National Research Foundation of Korea (NRF).

Data Availability Statement: Data is contained within the article.

Conflicts of Interest: The authors declare no conflict of interest. 


\section{References}

1. Mahmoudinezhad, S.; Atouei, S.A.; Cotfas, P.; Cotfas, D.; Rosendahl, L.A.; Rezania, A. Experimental and numerical study on the transient behavior of multi-junction solar cell-thermoelectric generator hybrid system. Energy Convers. Manag. 2019, 184, 448-455. [CrossRef]

2. Park, K.-I.; Xu, S.; Liu, Y.; Hwang, G.-T.; Kang, S.-J.L.; Wang, Z.L.; Lee, K.J. Piezoelectric $\mathrm{BaTiO}_{3}$ thin film nanogenerator on plastic substrates. Nano Lett. 2010, 10, 4939-4943. [CrossRef] [PubMed]

3. Wu, C.; Wang, A.C.; Ding, W.; Guo, H.; Wang, Z.L. Triboelectric nanogenerator: A foundation of the energy for the new era. Adv. Energy Mater. 2019, 9, 1802906. [CrossRef]

4. Wang, J.; Zhou, S.; Zhang, Z.; Yurchenko, D. High-performance piezoelectric wind energy harvester with Y-shaped attachments. Energy Convers. Manag. 2019, 181, 645-652. [CrossRef]

5. Yarlagadda, V.; Carpenter, M.K.; Moylan, T.E.; Kukreja, R.S.; Koestner, R.; Gu, W.; Thompson, L.; Kongkanand, A. Boosting fuel cell performance with accessible carbon mesopores. ACS Energy Lett. 2018, 3, 618-621. [CrossRef]

6. Juang, Z.-Y.; Tseng, C.-C.; Shi, Y.; Hsieh, W.-P.; Ryuzaki, S.; Saito, N.; Hsiung, C.-E.; Chang, W.-H.; Hernandez, Y.; Han, Y.; et al. Graphene-Au nanoparticle based vertical heterostructures: A novel route towards high-ZT Thermoelectric devices. Nano Energy 2017, 38, 385-391. [CrossRef]

7. Liu, S.; Lan, M.; Li, G.; Piao, Y.; Ahmoum, H.; Wang, Q. Breaking the tradeoff among thermoelectric parameters by multi composite of porosity and CNT in AZO films. Energy 2021, 225, 120320. [CrossRef]

8. Liu, S.; Li, G.; Lan, M.; Zhu, M.; Mori, T.; Wang, Q. Improvement of Thermoelectric Properties of Evaporated ZnO:Al Films by CNT and Au Nanocomposites. J. Phys. Chem. C 2020, 124, 12713-12722. [CrossRef]

9. Tambasov, I.A.; Voronin, A.S.; Evsevskaya, N.P.; Volochaev, M.N.; Fadeev, Y.V.; Simunin, M.M.; Aleksandrovsky, A.S.; Smolyarova, T.E.; Abelian, S.R.; Tambasova, E.V.; et al. Thermoelectric properties of low-cost transparent single wall carbon nanotube thin films obtained by vacuum filtration. Phys. E 2019, 114, 113619. [CrossRef]

10. Tomeda, A.; Ishibe, T.; Taniguchi, T.; Okuhata, R.; Watanabe, K.; Nakamura, Y. Enhanced thermoelectric performance of Ga-doped $\mathrm{ZnO}$ film by controlling crystal quality for transparent thermoelectric films. Thin Solid Films 2018, 666, 185-190. [CrossRef]

11. Yang, C.; Souchay, D.; Kneiß, M.; Bogner, M.; Wei, H.M.; Lorenz, M.; Oeckler, O.; Benstetter, G.; Fu, Y.Q.; Grundmann, M. Transparent flexible thermoelectric material based on non-toxic earth-abundant p-type copper iodide thin film. Nat. Commun. 2017, 8, 16076. [CrossRef] [PubMed]

12. Bell, L.E. Cooling, heating, generating power, and recovering waste heat with thermoelectric systems. Science 2008, 321, $1457-1461$. [CrossRef] [PubMed]

13. Hong, J.-E.; Lee, S.-K.; Yoon, S.-G. Enhanced thermoelectric properties of thermal treated $\mathrm{Sb}_{2} \mathrm{Te}_{3}$ thin films. J. Alloys Compd. 2014, 583, 111-115. [CrossRef]

14. Jeong, M.-W.; Na, S.; Shin, H.; Park, H.-B.; Lee, H.-J.; Joo, Y.-C. Thermomechanical in situ monitoring of $\mathrm{Bi}_{2} \mathrm{Te}_{3}$ thin film and its relationship with microstructure and thermoelectric performances. Electron. Mater. Lett. 2018, 14, 426-431. [CrossRef]

15. Loureiro, J.; Neves, N.; Barros, R.; Mateus, T.; Santos, R.; Filonovich, S.; Reparaz, S.; Sotomayor-Torres, C.M.; Wyczisk, F.; Divay, L. Transparent aluminium zinc oxide thin films with enhanced thermoelectric properties. J. Mater. Chem. A 2014, 2, $6649-6655$. [CrossRef]

16. Ali, H. Characterization of a new transparent-conducting material of ZnO doped ITO thin films. Phys. Status Solidi A 2005, 202, 2742-2752. [CrossRef]

17. Chung, S.M.; Shin, J.H.; Cheong, W.-S.; Hwang, C.-S.; Cho, K.I.; Kim, Y.J. Characteristics of Ti-doped ITO films grown by DC magnetron sputtering. Ceram. Int. 2012, 38, S617-S621. [CrossRef]

18. Fallah, H.R.; Ghasemi, M.; Hassanzadeh, A. Influence of heat treatment on structural, electrical, impedance and optical properties of nanocrystalline ITO films grown on glass at room temperature prepared by electron beam evaporation. Phys. E 2007, 39, 69-74. [CrossRef]

19. Hu, Y.; Diao, X.; Wang, C.; Hao, W.; Wang, T. Effects of heat treatment on properties of ITO films prepared by rf magnetron sputtering. Vacuum 2004, 75, 183-188. [CrossRef]

20. $\mathrm{Wu}, \mathrm{C}$; $\mathrm{Wu}, \mathrm{C}$; Sturm, J.; Kahn, A. Surface modification of indium tin oxide by plasma treatment: An effective method to improve the efficiency, brightness, and reliability of organic light emitting devices. Appl. Phys. Lett. 1997, 70, 1348-1350. [CrossRef]

21. Yang, C.-H.; Lee, S.-C.; Lin, T.-C.; Zhuang, W.-Y. Opto-electronic properties of titanium-doped indium-tin-oxide films deposited by RF magnetron sputtering at room temperature. Mat. Sci. Eng. B-Adv. 2006, 134, 68-75. [CrossRef]

22. Kang, Y.; Kwon, S.; Choi, J.; Cho, Y.; Song, P. Properties of Ce-doped ITO films deposited on polymer substrate by DC magnetron sputtering. Thin Solid Films 2010, 518, 3081-3084. [CrossRef]

23. Nomura, K.; Ohta, H.; Takagi, A.; Kamiya, T.; Hirano, M.; Hosono, H. Room-temperature fabrication of transparent flexible thin-film transistors using amorphous oxide semiconductors. Nature 2004, 432, 488-492. [CrossRef]

24. Lee, H.Y.; Yang, I.J.; Yoon, J.-H.; Jin, S.-H.; Kim, S.; Song, P.K. Thermoelectric Properties of Zinc-Doped Indium Tin Oxide Thin Films Prepared Using the Magnetron Co-Sputtering Method. Coatings 2019, 9, 788. [CrossRef]

25. Cocemasov, A.; Brinzari, V.; Jeong, D.-G.; Korotcenkov, G.; Vatavu, S.; Lee, J.-S.; Nika, D.L. Thermal transport evolution due to nanostructural transformations in Ga-doped indium-tin-oxide thin films. Nanomaterials 2021, 11, 1126. [CrossRef]

26. Lan, J.-L.; Liu, Y.; Lin, Y.-H.; Nan, C.-W.; Cai, Q.; Yang, X. Enhanced thermoelectric performance of $\operatorname{In}_{2} \mathrm{O}_{3}$-based ceramics via Nanostructuring and Point Defect Engineering. Sci. Rep. 2015, 5, 1-6. [CrossRef] [PubMed] 
27. Lide, D.R. CRC Handbook of Chemistry and Physics; CRC Press: Boca Raton, FL, USA, 2004; Volume 85.

28. Yagi, T.; Tamano, K.; Sato, Y.; Taketoshi, N.; Baba, T.; Shigesato, Y. Analysis on thermal properties of tin doped indium oxide films by picosecond thermoreflectance measurement. J. Vac. Sci. Technol. A 2005, 23, 1180-1186. [CrossRef]

29. Carreras, P.; Antony, A.; Roldán, R.; Nos, O.; Frigeri, P.A.; Asensi, J.M.; Bertomeu, J. Transparent conducting thin films by co-sputtering of ZnO-ITO targets. Phys. Status Solidi C 2010, 7, 953-956. [CrossRef]

30. Liu, D.-S.; Wu, C.-C.; Lee, C.-T. A transparent and conductive film prepared by RF magnetron cosputtering system at room temperature. Jpn. J. Appl. Phys. 2005, 44, 5119. [CrossRef]

31. Snyder, G.J.; Toberer, E.S. Complex thermoelectric materials. Nat. Mater. 2008, 7, 105-114. [CrossRef] [PubMed]

32. Ishibe, T.; Tomeda, A.; Komatsubara, Y.; Kitaura, R.; Uenuma, M.; Uraoka, Y.; Yamashita, Y.; Nakamura, Y. Carrier and phonon transport control by domain engineering for high-performance transparent thin film thermoelectric generator. Appl. Phys. Lett. 2021, 118, 151601. [CrossRef]

33. Liu, S.; Li, G.; Lan, M.; Zhu, M.; Miyazaki, K.; Wang, Q. Role of intrinsic defects on thermoelectric properties of ZnO:Al films. Ceram. Int. 2021, 47, 17760-17767. [CrossRef]

34. Petit, T.; Puskar, L. FTIR spectroscopy of nanodiamonds: Methods and interpretation. Diam. Relat. Mater. 2018, 89, 52-66. [CrossRef]

35. Winiarski, J.; Tylus, W.; Winiarska, K.; Szczygieł, I.; Szczygieł, B. XPS and FT-IR characterization of selected synthetic corrosion products of zinc expected in neutral environment containing chloride ions. J. Spectrosc. 2018, 2018, 2079278. [CrossRef]

36. Wu, N.C.; Shi, E.W.; Zheng, Y.Q.; Li, W.J. Effect of $\mathrm{pH}$ of medium on hydrothermal synthesis of nanocrystalline cerium (IV) oxide powders. J. Am. Ceram. Soc. 2002, 85, 2462-2468. [CrossRef]

37. Zamiri, R.; Abbastabar Ahangar, H.; Kaushal, A.; Zakaria, A.; Zamiri, G.; Tobaldi, D.; Ferreira, J. Dielectrical properties of CeO 2 nanoparticles at different temperatures. PLOS ONE 2015, 10, e0122989.

38. Petrov, T.; Markova-Deneva, I.; Chauvet, O.; Nikolov, R.; Denev, I. Sem and Ft-Ir Spectroscopy Study of Cu, Sn AND Cu-Sn Nanoparticles. J. Chem. Technol. Metall. 2012, 47, 2.

39. Zhu, G.; Guo, L.; Shen, X.; Ji, Z.; Chen, K.; Zhou, H. Monodispersed $\operatorname{In}_{2} \mathrm{O}_{3}$ mesoporous nanospheres: One-step facile synthesis and the improved gas-sensing performance. Sens. Actuators B Chem. 2015, 220, 977-985. [CrossRef]

40. Chang, K.-C.; Tsai, T.-M.; Chang, T.-C.; Zhang, R.; Chen, K.-H.; Chen, J.-H.; Chen, M.-C.; Huang, H.-C.; Zhang, W.; Lin, C.-Y. Improvement of resistive switching characteristic in silicon oxide-based RRAM through hydride-oxidation on indium tin oxide electrode by supercritical $\mathrm{CO}_{2}$ fluid. IEEE Electron. Device Lett. 2015, 36, 558-560. [CrossRef]

41. Raja, K.; Ramesh, P.; Geetha, D. Structural, FTIR and photoluminescence studies of Fe doped ZnO nanopowder by co-precipitation method. Spectrochim. Acta Part A Mol. Biomol. Spectrosc. 2014, 131, 183-188. [CrossRef] [PubMed]

42. Ali, A.; Ansari, A.A.; Kaushik, A.; Solanki, P.R.; Barik, A.; Pandey, M.; Malhotra, B. Nanostructured zinc oxide film for urea sensor. Mater. Lett. 2009, 63, 2473-2475. [CrossRef]

43. Liu, W.; Shi, X.; Hong, M.; Yang, L.; Moshwan, R.; Chen, Z.-G.; Zou, J. Ag doping induced abnormal lattice thermal conductivity in $\mathrm{Cu}_{2}$ Se. J. Mater. Chem. C 2018, 6, 13225-13231. [CrossRef] 